Psicologia Social Comunitária e Saúde Mental

\title{
Condições de vida, gênero e saúde mental entre trabalhadoras rurais assentadas
}

\author{
Maria da Graça Silveira Gomes da Costa \\ Universidade Potiguar \\ Magda Diniz Bezerra Dimenstein \\ Jáder Ferreira Leite \\ Universidade Federal do Rio Grande do Norte
}

\begin{abstract}
Resumo
O presente estudo teve como objetivo investigar a prevalência de transtornos mentais comuns (TMC) e os possíveis fatores relacionados à emergência de tais transtornos entre mulheres residentes de um assentamento rural do Rio Grande do Norte. Trata-se de uma pesquisa de caráter quantitativo e qualitativo de inspiração etnográfica. Como estratégias metodológicas, fizemos uso de questionário sócio-demográfico-ambiental, do instrumento de rastreamento em saúde mental Self-Reporting Questionnaire (SRQ-20) e de entrevista semiestruturada com as participantes. Os resultados apontam para a alta prevalência de TMC $(43,6 \%)$ entre as assentadas e sugerem a articulação entre pobreza, violência de gênero, sobrecarga laboral e a ocorrência de TMC.
\end{abstract}

Palavras-chave: transtornos mentais comuns; mulher; assentamento rural; determinantes sociais da saúde.

\begin{abstract}
Living conditions, gender and mental health among rural workers settled. The present study aims to investigate the prevalence of common mental disorders (CMD) and the possible factors related with the emergence of such disorders among women from a rural settlement in Rio Grande do Norte, Brazil. This survey has a quantitative and qualitative character with an ethnographic approach. As methodological strategies, we used a socio-demographic and environmental questionnaire, the mental health screening test Self-Reporting Questionnaire (SRQ-20), and semi-structured interview with the participants. The results point to the high prevalence of CMD (43.6\%) between the settled women and suggest the relationship between poverty, gender violence, overworking and the occurrence of CMD.
\end{abstract}

Keywords: common mental disorders; woman; rural settlement; social determinants of health

\section{Resumen}

Condiciones de vida, género y salud mental entre trabajadoras rurales asentadas. El presente estudio pretende investigar la prevalencia de trastornos mentales comunes (TMC) y los posibles factores relacionados con la aparición de estas enfermedades entre las mujeres residentes de un asentamiento rural de Rio Grande do Norte, Brasil. Metodológicamente, es una investigación que parte de un enfoque cuantitativo y cualitativo de inspiración etnográfica. Como estrategias metodológicas, se aplicó un cuestionario socio-demográfico-ambiental, el cuestionario de detección en salud mental Self-Reporting Questionnaire (SRQ-20) y entrevista semiestructurada con las participantes. Los resultados señalan a la alta prevalencia de TMC $(43,6 \%)$ entre las mujeres asentadas y sugieren vínculos entre la pobreza, la violencia de género, exceso de trabajo y la ocurrencia de TMC.

Palabras clave: trastornos mentales comunes; mujer; asentamiento rural; determinantes sociales de la salud.

A grande concentração de terras e as desigualdades sociais entre o campo e a cidade mostram como o -processo de desenvolvimento do capitalismo no meio rural brasileiro se deu à custa da exclusão social da maior parte da população do país. A estrutura fundiária e agrícola do Brasil é marcada, historicamente, pelo grande latifúndio e exploração do meio ambiente, em detrimento do incentivo à agricultura familiar e sustentável. O desenvolvimento da economia capitalista no meio rural brasileiro, denominado por Delgado (2001) como "modernização conservadora" da agricultura, foi o fator desencadeador de algumas das mais graves alterações ambientais nas áreas de cultivo agrícola no país, como a devastação de florestas tropicais, a destruição da biodiversidade, a erosão e a desertificação, além de ter aumentado a 
precarização das relações de trabalho no campo (Pinheiro, Silva, Carneiro, \& Faria, 2009). Não por acaso, é na área rural que são encontrados os maiores índices de insegurança alimentar, mortalidade infantil, incidência de endemias, insalubridade e analfabetismo no Brasil, caracterizando uma situação de enorme pobreza decorrente das restrições de acesso aos bens e serviços indispensáveis à vida (Ministério da Saúde, 2005).

Apesar da relativa escassez de investigações voltadas às questões de saúde mental em populações rurais, a literatura vem mostrando que os residentes dessas áreas, de maneira geral, e os trabalhadores rurais em particular, representam uma parcela da população que possui um risco substancialmente maior que a população geral para o desenvolvimento de problemas em relação à saúde mental (Costa \& Ludemir, 2005; Faria, Facchini, Fassa, \& Tomasi, 2000). A literatura também aponta que, tanto no contexto rural quanto urbano, as mulheres são ainda mais vulneráveis ao surgimento de transtornos mentais comuns (Ludermir, 2008; World Health Organization [WHO], 2002).

A expressão transtorno mental comum (TMC) foi criada por Golberg e Huxley (1992) para caracterizar quadros sintomáticos não psicóticos e sem patologia orgânica associada, como insônia, fadiga, irritabilidade, esquecimento, dificuldade de concentração e queixas somáticas que, além de causarem intenso sofrimento psíquico, geram incapacidade funcional comparável ou até pior aos quadros crônicos já estabelecidos (Maragno, Goldbaum, Giani, Novaes, \& Cesar, 2006).

Como apontam Araújo, Pinho e Almeida (2005), tem-se observado que os indivíduos com TMC apresentam taxas de mortalidade mais altas e, em média, duas vezes mais queixas em relação à saúde física do que a população geral. Já Ludermir e Melo Filho (2002) destacam que estudos epidemiológicos têm verificado a associação entre TMC e variáveis relativas às condições de vida e trabalho, havendo uma prevalência de TMC significativamente mais alta entre pessoas que se encontram em condições de maior vulnerabilidade econômica e psicossocial, de forma que a classe social, o gênero e a situação laboral são apontados como os principais determinantes sociais em relação ao bem-estar emocional e o desenvolvimento de transtornos de caráter psicossomáticos nos sujeitos (Álvaro, Torregrosa, \& Luque, 1992). É importante ressaltar que apesar da relevância dos dados relativos à saúde mental das mulheres em todo o mundo, a grande parte das pesquisas acadêmicas e dos programas voltados à saúde da mulher no Brasil, tanto por parte das políticas governamentais, quanto pelo terceiro setor e movimento feminista, é voltada exclusivamente para a questão da saúde sexual e reprodutiva.

Acreditando na necessidade de pesquisar mais a fundo acerca das demandas de saúde mental das mulheres assentadas e trabalhadoras rurais, trataremos no presente artigo da relação entre condições de vida, trabalho e saúde mental das mulheres no contexto rural. Para tanto, investigamos a prevalência de TMC e os possíveis fatores relacionados à sua emergência entre mulheres residentes de um assentamento rural na região do Mato Grande no estado do Rio Grande do Norte (RN). Buscamos entender essa relação a partir do contexto socioeconômico e ambiental em que vive essa população, analisando os fatores identificados pelas mulheres como possíveis deflagradores desses transtornos.

Os assentamentos são dispositivos catalisadores de uma série de processos sociais que possibilitam o empoderamento de um grande número de trabalhadores rurais sem terra ao permitir o acesso à propriedade da terra para uma população historicamente excluída. Desse modo, se configuram como unidades produtivas agrícolas criadas por meio da ação do Estado com vistas à redistribuição de terras em benefício de trabalhadores rurais familiares (Bergamasco \& Norder, 1996).

A região do Mato Grande, por sua vez, é um cenário representativo da atual realidade das áreas rurais no Nordeste brasileiro, pois, tendo sido palco de alguns dos maiores conflitos de terras do RN, principalmente durante as décadas de 1980 e 1990, conta, até os dias de hoje, com uma grande concentração de assentamentos, acampamentos e latifúndios. No presente texto, procuramos pensar esses espaços não apenas como meios de produção material, mas a partir da dimensão da subjetividade e da saúde mental em sua relação com a terra e o território.

\section{Método}

Partimos de uma abordagem metodológica quantitativa e qualitativa desenvolvida em três etapas. Na primeira, buscamos conhecer as condições gerais de vida, moradia, saúde, meio ambiente e perfil socioeconômico das famílias residentes no assentamento através de questionário sócio-demográfico -ambiental. Apesar do número oficial de 61 famílias cadastradas pelo Instituto Nacional de Colonização e Reforma Agrária (INCRA) no assentamento, muitas delas não vivem mais na comunidade e outras passam parte do ano trabalhando em outros municípios, o que torna muito difícil precisar quantas pessoas moram, de fato, na comunidade. A partir de um mapeamento prévio, foram identificadas 43 famílias residentes que responderam os questionários.

Na segunda etapa, rastreamos os casos indicativos de TMC entre as mulheres adultas do assentamento a partir do uso do Self-Reporting Questionnaire (SRQ-20), instrumento desenvolvido pela Organização Mundial de Saúde para identificar casos de suspeita de TMC em populações de países em desenvolvimento. Para a realização do presente estudo, utilizamos a versão do SRQ-20 traduzida para a língua portuguesa e validada no Brasil por Mari e Williams (1986). O instrumento consiste em vinte perguntas fechadas sobre o estado de saúde mental em que o sujeito se encontra nos últimos 30 dias. Cada item é pontuado de acordo com a presença ou não dos sintomas no último mês. As respostas afirmativas sinalizam a presença de sintomas e tem pontuação igual a 1 enquanto as respostas negativas indicam ausência de sintomas e têm pontuação igual a 0 . Em escores acima ou igual a 7 (sendo o escore máximo igual a 20) foi levantada a hipótese de TMC, levando em consideração o critério empregado na maioria dos estudos nacionais que utilizam esse instrumento (Araújo et al., 2005; Ludermir \& Melo Filho, 2002; Maragno et al., 2006). 
A partir dos dados do questionário sócio-demográfico-ambiental identificamos 61 mulheres acima dos 18 anos de idade na comunidade, sendo essa a nossa meta inicial para a realização do rastreamento de TMC entre a população feminina do assentamento. Dessas, 55 mulheres aceitaram participar de nosso estudo respondendo o SRQ-20.

$\mathrm{Na}$ terceira etapa buscamos conhecer os fatores identificados pelas mulheres como possíveis deflagradores de transtornos. Nessa etapa foram realizadas entrevistas semiestruturadas com 22 mulheres que apresentaram indicativo de TMC e demonstraram interesse em participar. As falas das participantes foram categorizadas a partir da análise de conteúdo temático-categorial (Bardin, 1977).

\section{Resultados e discussão}

O RN tem, segundo dados do INCRA (2012), 293 assentamentos onde vivem 20.008 famílias. O estado é divido pelo INCRA em nove sub-regiões geográficas: Mato Grande, Alto Oeste, Potengi, Seridó, Sertão do Apodi, Sertão Central, Terra dos Potiguaras, Trairí e Agreste. A região do Mato Grande fica no litoral norte do estado. $O$ assentamento pesquisado foi criado no ano de 2007, através do processo de luta que culminou na desapropriação da área ocupada.

Através do questionário sócio-demográfico-ambiental identificamos 195 moradores na comunidade. A maior parte dos assentados são agricultores e/ou criadores de animais, sendo que o sustento das famílias é, em sua maioria, proveniente da agricultura familiar de subsistência, de programas sociais do governo e de aposentadoria. Quase todas as famílias da comunidade $(84,1 \%)$ recebem o benefício do Programa Bolsa Família ${ }^{1}$, enquanto apenas $25,0 \%$ das famílias acessam outros programas sociais do governo federal. A grande maioria das famílias residentes $(84,2 \%)$ vive com até um salário mínimo por mês. Durante o período do verão, as famílias complementam a renda através da venda da colheita de mangaba e caju, plantas nativas que existem em abundância no espaço do assentamento que costumava ser uma fazenda produtora de castanhas de caju para exportação antes da falência e posterior desapropriação.

Somente duas famílias declaram fazer uso de agrotóxicos na produção, no entanto observamos no convívio com a comunidade que mais famílias utilizam agrotóxicos e assim o fazem de uma maneira não sistematizada e sem o uso dos equipamentos de segurança necessários, revelando grande desinformação por parte dos assentados acerca dos riscos que envolvem o manejo desse tipo de substância.

Ainda em relação à produção, $75,7 \%$ das famílias não possuem sistema de irrigação e $51,4 \%$ utilizam apenas ferramentas manuais como implementos agrícolas na produção. Boa parte das famílias não recebe nenhum tipo de assistência técnica para a produção (67,6\%), o que nos pareceu bastante problemático, pois também aumenta, sobremaneira, os riscos de agravo à saúde dos trabalhadores. Os trabalhadores rurais têm demandas particulares relacionadas às suas condições de trabalho, por tal razão necessitam de informação em relação ao uso de equipamentos de proteção individual, sobre o alto esforço físico demandado pelo lido com a roça, dentre outras questões que não vêm sendo atendidas (Fontoura Jr., Renovato, \& Sales, 2012).

Em relação à educação, 16,4\% dos adultos são analfabetos ou frequentaram a escola por menos de um ano, $57,4 \%$ tem ensino fundamental, $15,9 \%$ ensino médio e apenas $0,5 \%$ chegaram ao ensino superior. Grande parte das famílias da comunidade é oriunda de áreas rurais e 31,8\% reside na área do assentamento desde a época do acampamento e da ocupação organizada pelo Movimento dos Trabalhadores Rurais Sem Terra (MST).

Moram, em média, quatro pessoas por domicílio (36,1\%) em casas de seis cômodos (31,8\%). O abastecimento da água para as famílias é feito, quase em sua totalidade $(73,7 \%)$, através de poço artesiano e o armazenamento é feito em caixa-d'água e tambor. Quanto à água potável, 68,4\% das famílias não fazem nenhum tipo de tratamento. Todas as casas possuem fossa séptica. O lixo não orgânico das famílias é, em geral, queimado (o que, segundo os moradores, empobrece o solo) enquanto o lixo orgânico é enterrado nos próprios lotes podendo também servir para alimentação de animais de pequeno porte.

No que diz respeito às condições de saúde, todas as famílias têm acesso a algum tipo de serviço ou programa de saúde e 93,8\% delas são atendidas pelo Programa Agentes Comunitários de Saúde (PACS) via Estratégia Saúde da Família (ESF). Mais de $80 \%$ das famílias utilizam o posto de saúde do assentamento que funciona uma vez por mês (nos meses em que há alguma regularidade), quando há visita do médico e do agente comunitário de saúde. Esses profissionais estão ligados à ESF que conta, ao todo, com três equipes modalidade I - voltadas para o atendimento de populações residentes em assentamentos rurais ou remanescentes de quilombos - e um Núcleo de Apoio à Saúde da Família (NASF). Em caso de necessidade de internação hospitalar todas as famílias recorrem ao hospital regional que fica a $30 \mathrm{~km}$ do assentamento. Há uma boa cobertura de vacinação $(90,9 \%)$, mas o acesso aos medicamentos via farmácia popular ainda é precário.

Não há, na região, serviços especializados de saúde mental, ambulatórios, nem leitos psiquiátricos - os Centros de Atenção Psicossocial (CAPS AD e II) mais próximos também ficam em cidades distantes do território do assentamento, sendo esses os serviços de referência da Rede de Atenção Psicossocial para essa população.

Em termos de morbidade registra-se pouca ocorrência de doenças infectocontagiosas e doenças sexualmente transmissíveis (DST's), porém é alto o percentual de diarreias (45,5\%), gripes $(97,7 \%)$, dengue $(29,5 \%)$ e verminoses $(36,4 \%)$ associadas às condições sanitárias locais e à má qualidade da água. Grande parte da população estudada apresenta problemas de hipertensão $(34,2 \%)$ e há ainda registro de casos de tuberculose e desnutrição em algumas famílias. Ainda em relação à saúde, registramos que é frequente o uso da medicina popular 
com chás (84,1\%), lambedores (88,6\%), e garrafadas $(61,4 \%)$ entre os moradores.

Quanto às mulheres da comunidade, elas são, em sua maioria, jovens e adultas que se encontram na faixa etária dos 18 aos 49 anos de idade (73,4\%). Grande parte delas é casada ou vive em união estável (73,9\%). No tocante à ocupação, quase todas são agricultoras/criadoras de animais e donas de casa (82,6\%), 3,3\% são aposentadas, 8,6\% são comerciantes, $4,3 \%$ são estudantes e $4,0 \%$ não responderam e/ou não têm ocupação.

No que se refere à escolaridade, $50 \%$ são analfabetas e, entre aquelas que estudaram, a maioria só chegou a completar até a $8^{\mathrm{a}}$ série do ensino fundamental. Notamos ainda que, na época da aplicação dos questionários, a participação política das mulheres em movimentos sociais, sindicatos e outras esferas de inserção política era menor do que entre os homens; no entanto, esse cenário foi sendo modificado durante o tempo em que acompanhamos essa comunidade com a organização das mulheres em torno de uma associação própria. Essa associação tem como objetivo viabilizar um projeto de produção de doces caseiros e apoiar a participação das produtoras em dispositivos institucionalizados de disputa política como o Fórum de Trabalhadores Rurais, espaço organizado onde se discute, junto com as respectivas associações, questões relativas aos assentamentos rurais da região.

Esses dados nos mostram que as famílias da comunidade estudada têm uma série de vulnerabilidades econômicas, psicossociais e ambientais, tendo pouco acesso aos serviços básicos de saúde e educação, convivendo com uma infraestrutura precária; com recurso limitado de água; apresentando dificuldades em relação à produção agrícola e à venda de seus produtos; além da falta de redes de apoio social e organização coletiva, entre outras questões. Essa situação se agrava ainda mais quando analisamos os dados específicos das mulheres, que apresentam taxas mais altas de analfabetismo, de problemas de saúde e menor autonomia financeira.

Buscando avaliar a relação entre transtornos mentais e as iniquidades sociais e de saúde no Brasil, Silva e Santana (2012) realizaram uma revisão sistemática da literatura científica referente ao período de 2004 a 2009. Os autores verificaram, dentre outras coisas, que os estudos mostraram ser a desigualdade social no país um fator associado a problemas de saúde mental na população; que fatores como baixa escolaridade e gênero feminino quando associados à pobreza aumentam a prevalência de TMC; que a situação econômica compromete igualmente a saúde mental infantil; e que em virtude dos resultados mostrarem que os transtornos mentais vão além dos fatores apenas individuais, a formulação de políticas públicas deve considerar as desigualdades com o objetivo de prevenir os TMC.

Deparamo-nos, através do rastreamento em 55 mulheres adultas da comunidade, com um total de 24 mulheres $(43,6 \%)$ que apresentaram indicativo de TMC (escore $\geq 7$ ). Vemos que a alta porcentagem de casos de suspeição diagnóstica de TMC levantada entre as mulheres está de acordo com o cenário descrito pela maior parte dos estudos acadêmicos sobre o tema.
Costa e Ludermir (2005) encontraram entre 483 trabalhadores rurais da Zona da Mata no estado de Pernambuco uma incidência de TMC de 36,0\% na população total, sendo a prevalência entre as mulheres igual a $44,2 \%$ e entre os homens a $24,5 \%$. Ao relacionarem a ocorrência de TMC ao apoio social, incluindo a situação conjugal, os autores demonstraram ainda que as pessoas com baixo apoio social têm duas vezes mais chances de desenvolver TMC. Já Faria et al. (2000) também encontraram uma prevalência de TMC de $36 \%$ em pesquisa realizada com 1.479 trabalhadores rurais da Serra Gaúcha, sendo a prevalência no sexo masculino de $31,6 \%$ e no sexo feminino de $42,5 \%$.

Seguindo o modelo sugerido por Iacoponi e Mari (1988) classificamos as respostas em fatores por grupos de sintomas que compunham dimensões específicas, identificadas como: fator I - humor depressivo/ansioso; fator II - sintomas somáticos; fator III - decréscimo de energia vital; fator IV pensamento depressivo. $\mathrm{Na}$ análise por grupos de sintomas, observamos que os fatores mais expressivos foram os correspondentes aos sintomas somáticos e humor depressivo/ ansioso, o que também corrobora com uma série de estudos que mostram que, tanto em áreas rurais quanto urbanas, as mulheres apresentam maior prevalência de depressão, transtornos relacionados à somatização, transtorno de ansiedade generalizada, fobias de pânico e transtornos alimentares (Bandeira, Freitas, \& Carvalho Filho, 2007; Coutinho, Rodrigues, \& Ramos, 2012; Maragno et al., 2006; WHO, 2002). De acordo com Oliveira-Couto (2007), as mulheres em todo o mundo são duas vezes mais suscetíveis à depressão que os homens, caracterizando-a como uma enfermidade predominantemente feminina. É importante ressaltar que a literatura aponta que tal disparidade entre homens e mulheres no que se refere à prevalência de depressão é ainda mais significativa entre populações que vivem em condições de pobreza e carência estrutural (WHO, 2000).

\section{Gênero, trabalho e saúde: Os fatores relacionados ao sofrimento}

As mulheres manifestaram vários sintomas como insônia, choro constante, falta de apetite, etc., que foram identificados por elas comumente como "doença nos nervos", "nervoso" ou "sistema nervoso". Tais expressões nos remetem ao trabalho de Duarte (1986) sobre o uso da categoria nervoso pelas classes trabalhadoras. De acordo com o autor, os nervos são pensados como um meio físico de experiências tanto físicas quanto morais que se opõem ao modelo individual de psiquismo dos segmentos portadores dos saberes biomédicos eruditos, dominantes e oficiais (Duarte, 1994; 2003).

A categoria "nervos" e suas expressões surgem enquanto idioma social da doença, do sofrimento e da aflição, por meio do qual as pessoas conferem significados às suas experiências de enfermidade. As narrativas de aflição possuem um papel fundamental, na medida em que "constituem estratégias de inovação semântica, que estendem sentidos habituais para domínios inesperados, oferecendo assim uma ponte entre a singularidade da experiência e objetividade da linguagem, das 
instituições e dos modelos legitimados socialmente" (Alves \& Rabelo, 1999, p.173).

Assim, o conceito de "nervos" não pode ser pensado como uma doença que possui uma causa única, tal como os sintomas das doenças tipificados e categorizados pela biomedicina numa perspectiva naturalista e biologizante. Essa proposta heurística enfatiza a dimensão social e cultural da condição de estar doente e nos ajuda a entender a experiência subjetiva das mulheres no contexto do assentamento.

As mulheres entrevistadas associaram esse "sistema nervoso" a uma série de acontecimentos que teriam desencadeado ou agravado tais sentimentos. Os principais fatores identificados pelas participantes no que se refere ao sofrimento em sua saúde física e mental foram a pobreza, o casamento, a sobrecarga de trabalho e a violência (principalmente a violência doméstica e sexual).

Ao realizar as entrevistas, escutamos, com alguma surpresa que, para a maior parte das mulheres, o casamento (ou união estável) era uma das maiores fontes de angústia para as assentadas. Fomos entendendo aos poucos que, na agricultura familiar, esses relacionamentos e tudo aquilo o que os envolve - a chegada dos filhos, o cuidado com a casa - têm um papel central na lógica de organização dos grupos domésticos como orientadora para a vida social no campo.

Além de estar relacionado ao aumento de responsabilidade, o casamento também representa um aumento da carga de trabalho. No âmbito doméstico, o trabalho das mulheres assegura a reprodução social e o bem-estar dos membros da família. Para Melo e Di Sabbato (2009), o fato de as mulheres realizarem várias atividades ao mesmo tempo dificulta $\mathrm{e}$ limita a avaliação do tempo gasto com as tarefas domésticas e isso explica "por que uma mulher casada tem mais trabalho doméstico do que uma que vive sozinha, quando deveria se esperar uma diminuição da carga de trabalho em função da existência de dois adultos" (p. 19). Dessa forma, percebe-se que, na área rural, as mulheres têm uma "tripla jornada de trabalho", trabalho esse que muitas vezes é "invisível" e que as sobrecarregam:

O trabalho rural [feminino] ocorre em uma jornada contínua, do amanhecer até tarde da noite, sem tempo para lazer e para si. O espaço também é pouco separado entre a casa e o quintal, muitas vezes sem distinção entre o que é espaço doméstico e aquele destinado ao trabalho produtivo, o que faz com que a sobrecarga de trabalho seja muito maior que a dos homens, muito embora o reconhecimento social como trabalhadora seja bem menor e os ganhos, em termos de renda, mais reduzidos ainda (Silva, 2011, p. 108).

De acordo com dados da Pesquisa Nacional por Amostra de Domicílios/PNAD (Instituto Brasileiro de Geografia e Estatística [IBGE], 2011), as mulheres brasileiras gastam uma média de 26,6 horas por semana em afazeres domésticos, enquanto os homens só dedicam 10,5 horas a essa atividade. Tal tendência é mantida ainda entre os trabalhadores assalariados de ambos os sexos: 22 horas entre as mulheres em comparação com 9,5 horas entre os homens.

Além da carga do trabalho doméstico, do ponto de vista de gênero, o processo de exclusão ou de inserção precária da força de trabalho nas atividades econômicas não foi homogêneo, sendo mais intenso para a população feminina, o que contribuiu para o processo de "feminização da pobreza"2 (Campos, 2011). Notamos que no assentamento em questão, as mulheres são, em geral, responsáveis por buscar e armazenar a água da casa, coletar frutos e cuidar dos animais, pela produção de doces caseiros, cuidado da casa e da família, mas também assumem, frequentemente, o trabalho de preparação do solo, plantio, cultivo e colheita de alimentos e roçado para consumo junto aos seus companheiros. Muitas mulheres realizam a totalidade do trabalho agrícola em suas famílias, pois é considerável o número de homens que trabalham fora fazendo bicos, vendendo a produção das famílias ou cortando lenha. No entanto, a maioria das decisões sobre a produção e a utilização dos recursos financeiros ainda cabem aos homens que também tomam à frente nas questões gerais do assentamento, como inscrição em projetos de fomento à produção agrícola e aquisição coletiva de insumos.

Da mesma forma, as mulheres estão ainda longe de certos tipos de atividades, especialmente as relacionadas com a vida pública e a comercialização da produção. Mesmo nos casos em que elas participam na venda, muitas vezes corresponde ao homem a gestão dos recursos. De acordo com Melo, Cappelin e Castro (2008), a invisibilidade do trabalho das mulheres nas zonas rurais manifesta-se também no processo de tomada de decisão. As mulheres têm dificuldade em serem reconhecidas como produtoras, uma vez que em grande parte das unidades familiares o homem aparece como o chefe da propriedade, que toma as decisões sobre a gestão do uso do solo e dos recursos econômicos.

Esse "status" diferenciado é especialmente prejudicial para as mulheres no que se refere ao acesso às políticas públicas, linhas de crédito e benefícios de previdência social como a aposentadoria enquanto trabalhadora rural. Butto (2011) destaca que são muito recentes as políticas de desenvolvimento rural no Brasil que levam em conta e reconhecem o trabalho das mulheres na agricultura, buscando a promoção da igualdade de gênero, como as políticas públicas levadas a cabo pelo Governo Federal a partir da implantação das propostas formuladas no I Plano Nacional de Políticas para as Mulheres (Secretaria de Políticas para as Mulheres [SPM], 2004) e os projetos desenvolvidos pelo Ministério do Desenvolvimento Agrário que possui, desde 2008, a Diretoria de Políticas para as Mulheres Rurais que tem como objetivo a promoção de ações que visam reparar as condições desiguais de gênero entre as populações do campo e da floresta levando em conta suas especificidades.

Problematizando a relação trabalho-saúde, Dejours (1992) defende que o trabalho nunca é neutro em relação à saúde, podendo tanto favorecê-la quanto contribuir para adoecimento. Deste modo, de acordo com Neves e Silva (2006), faz-se necessária não apenas a verificação mecânica dos "impactos" do trabalho "sobre" os indivíduos, mas uma análise que leve à compreensão da complexidade da dinâmica das relações sociais. A tripla jornada de trabalho foi citada por algumas entrevistadas como sendo um fator gerador de muito sofrimento e problemas de saúde, como nos mostram a fala de Margarida ${ }^{3}$, de 50 anos: 
Eu trabalho muito pesado, carrego muito peso e quando chego em casa ainda tenho que fazer as coisa. Acordo todo dia às três da manhã pra fazer a comida pros menino ir pra escola. Tem dia que eu saio sozinha no meio desses mato, sem carroça nem nada (...) Eu sou uma pessoa doente, eu num posso trabalhar, mas tenho que trabalhar porque não tenho quem dê nada por mim. Ou eu morro de trabalho ou eu morro de fome (Margarida, mulher assentada).

A dificuldade na produção, na colheita (especialmente em anos com pouca chuva) e na comercialização dos produtos é um agravante que gera incerteza, estresse e muitas dificuldades financeiras na comunidade. Vale ressaltar que, dos 167 municípios do RN, 147 encontram-se inseridos na região do semiárido que é mais vulnerável à ocorrência de secas, como é o caso do território em que se encontra o assentamento em questão, o que demanda uma série de investimentos específicos em relação à irrigação e ao cuidado com o solo para implantação de projetos de produção agropecuária no estado. De acordo com o IBGE (2013) o RN perdeu, no ano de 2012, 29\% da área total colhida devido à estiagem, ficando assim, com uma das mais baixas taxas de produção agrícola entre os estados do país. Algumas comunidades, como no caso do assentamento pesquisado, que não possuem projetos de irrigação e dependem, basicamente, da agricultura de sequeiro ${ }^{4}$, sentem mais fortemente esse processo. Além disso, a falta de estradas em boas condições e de transporte público na área dificulta a saída do assentamento para a venda dos produtos, além de limitarem o número de compradores que, na maioria das vezes, "impõem" seus preços de compra em valores muito abaixo do mercado. Acácia, 39 anos, relata como as dificuldades financeiras afetam sua saúde mental:

Hoje eu saí pra feira preocupada, louquinha da minha cabeça, digo: Meu Deus, eu vou ver o que na feira hoje, sem dinheiro? Trabalhei duas semanas, não recebi um centavo, o dinheiro tá tudo acolá, o dinheiro da mangaba, só chega... ainda arrumei um dinheiro emprestado, vou arrumar um dinheiro emprestado e comprar ao menos, a comida pro boi, e comprar alguma mistura pra passar a semana. Aí de lá pra cá a cabeça apertou (Acácia, mulher assentada).

Diante desse contexto, os assentados têm de criar estratégias de complementação da renda familiar. Segundo as entrevistadas, vem crescendo na comunidade o número de mulheres que são trabalhadoras domésticas diaristas (de forma esporádica ou fixa) em outras cidades da região e na capital ou fazem vendas de produtos de maneira informal, como no caso das doceiras e das revendedoras de cosméticos. A maioria das mulheres não citou essas funções ao responder o questionário, pois consideram tais ocupações como "bicos", que não representam a sua atividade oficial.

Algumas mulheres nos confessaram ainda que mesmo quando têm as atividades não-agrícolas como principais fontes de renda elas se declaram como trabalhadoras rurais, por orientação de integrantes dos movimentos do campo e de alguns técnicos do INCRA, o que mostra o papel desses dispositivos políticos e sociais no próprio processo de reconhecimento das mulheres enquanto campesinas. Nesses casos, elas têm o poder de gestão sobre os próprios ganhos financeiros, o que pode gerar uma maior autonomia financeira e um possível empoderamento, ao mesmo tempo em que pode aumentar suas cargas de trabalho, sem trazer mudanças significativas nas relações de poder e gênero dentro de suas famílias. Também não podemos desconsiderar a importância das políticas sociais compensatórias como o Programa Bolsa Família (PBF) no processo de empoderamento econômico dessas mulheres, pois cabe a elas a gestão dos recursos advindos do benefício. No entanto, mais uma vez tem que se levar em conta a sobrecarga de tarefas que um programa de transferência condicional ${ }^{5}$ de renda como o PBF traz às mulheres ao reforçar os papeis de gênero encarregando a mulher da responsabilidade pelo cuidado da saúde da família e pela educação dos filhos.

Outra importante variável a ser levada em consideração no processo de sofrimento psíquico das assentadas é a violência. Essa questão representa um significativo problema social e de saúde pública que atinge mulheres de todas as idades, etnias e classes sociais (Santos, 2009) e é considerada pela Organização Mundial de Saúde (WHO, 2002) como a principal causa de depressão entre as mulheres em todo o mundo.

Estudos em diversos países mostram a relação entre o desenvolvimento de problemas em relação à saúde mental e a violência de gênero entre as mulheres e que, na grande maioria dos casos, esse tipo de violência é cometido pelos cônjuges ou pessoas próximas às vítimas. Através de revisão da literatura de pesquisas realizadas em países em desenvolvimento acerca da associação entre violência e saúde mental, Ribeiro, Andreoli, Ferri, Prince e Mari (2009) averiguaram que, entre as mulheres, os sintomas de depressão e ansiedade estão quase sempre correlacionados com violência conjugal psicológica e violência sexual.

O casamento e a união estável também aparecem relacionados ao início dos episódios de violência para boa parte das entrevistadas. Ao ser questionada sobre como os sintomas de sofrimento que relatava haviam começado, Margarida, uma das mulheres que apresentou mais sintomas de ansiedade e depressão, respondeu que:

Comecei a sentir esses problemas eu tinha 35 anos, quando eu comecei a sentir esses problemas de doença de tudo assim... Eu tinha na base dos 35 , foi na época que eu morei com o pai do menino, me perturbei muito, sofri muito, né? Nas mãos dele, sofri demais, vivia sendo espancada, judiada, apanhada, levava chute, eu ia parar no hospital, tudo isso, de tanto ele me judiar e bater tanto na minha cabeça, bater no meu corpo que hoje eu estou sentindo esses problemas através disso, eu penso que é através do pai dos meus filhos (Margarida, 49 anos, mulher assentada).

Algumas mulheres também associaram os sintomas com episódios de violência sexual, como Flor de 38 anos:

\footnotetext{
Começou a partir do momento que, eu já estava casada, antes de eu casar, né? Que estava namorando com uma pessoa e a pessoa assim, eu namorei uma pessoa e a pessoa, praticamente foi tipo um estupro, né? Só que meus pais não sabiam, e praticamente eu fugi com ele por medo, tipo, porque na época meus pais eram muito rígidos, principalmente minha mãe, então, se eu fosse falar o que tivesse acontecido ela ia cada vez me culpar, então, eu me assujeitei me juntar com ele (Flor, mulher assentada).
}

O processo de "culpabilização" da vítima de violência sexual, como mostrado na história de Flor, é um dos mais eficientes 
mecanismos de dominação do corpo feminino engendrado na sociedade patriarcal. Vítimas desse tipo de violência, em geral, têm muita vergonha e não denunciam seus agressores ou são, ainda, desencorajadas a denunciá-los como mostram os dados da pesquisa sobre violência contra mulheres no contexto rural realizada por Cordeiro (2007) no sertão pernambucano.

É importante ressaltar que, entre as mulheres que relataram casos de violência doméstica, todas vivenciaram mais de um episódio de violência e, em geral, com mais de um companheiro. Segundo estimativas da Confederação Nacional dos Trabalhadores na Agricultura (CONTAG, 2008), 55\% das mulheres do campo já sofreram algum tipo de agressão ou abuso sexual. Apesar dos grandes avanços conseguidos a partir da promulgação da Lei Maria da Penha ${ }^{6}$, as políticas de enfretamento à violência contra mulher ainda não atingem, de forma eficaz, as mulheres do campo e da floresta, sendo essa uma das maiores bandeiras de lutas dos movimentos de mulheres camponesas na atualidade. Entre as dificuldades apontadas pelas mulheres do campo, estão as distâncias das Delegacias Especializadas de Atendimento à Mulher (DEAM) que ainda não estão presentes de forma massiva no interior do país e, principalmente, o padrão rígido e assimétrico das relações de gênero na área rural (Cordeiro, 2007)

\section{Considerações finais}

Observamos na comunidade em questão uma combinação de riscos socioeconômicos e ambientais que impactam a qualidade de vida, sendo produtores de estresse e que podem estar relacionados às condições de saúde e, em particular, ao desenvolvimento de transtornos mentais comuns. Entretanto, é importante ressaltar que devido ao limitado tamanho da amostra estudada e ao tipo de análise realizada, não podemos associar estatisticamente tais fatores.

Os resultados encontrados em nossa investigação apontam para a situação de grande vulnerabilidade psicossocial em que vivem os assentados e corroboram o perfil apresentado em vários estudos socioeconômicos, epidemiológicos e ambientais com populações residentes em áreas rurais no país (Aucélio, Godoi, \& Moraes, 2001; Carneiro et al., 2008; IBGE, 2010; Maciel, Rigotto, \& Alves, 2011). De maneira geral, ainda existem grandes limitações em relação ao acesso e à qualidade dos serviços de saúde, bem como uma situação deficiente de saneamento ambiental nas áreas rurais. O processo de "modernização conservadora" da agricultura ainda tem agravado mais esse quadro, uma vez que criou novos riscos socioambientais para a saúde dessas populações (Pinheiro et al., 2009).

No caso do assentamento estudado, os moradores estão sujeitos à instabilidade climática da região devido aos períodos de seca e estiagem, à escassez de recursos naturais, a não implementação e/ou mau uso das políticas de crédito agrícola e assistência técnica, ao transporte precário, necessitam desenvolver estratégias de complementação da renda familiar e carecem de organização coletiva e participação política para que possam produzir interferência nos padrões de desenvolvimento local, de saúde e na vida comunitária.

A degradação ambiental, a alimentação inadequada e o baixo nível de apoio social são fatores relacionados ao aumento das doenças crônico-degenerativas, bem como a presença de morbidades psiquiátricas. Nesse cenário, a carga do trabalho doméstico e agrícola e a violência de gênero aparecem como agravantes que aumentam, sobremaneira, a situação de vulnerabilidade das mulheres em relação à saúde mental.

Dessa forma, observamos que a pobreza, a carência de infraestrutura, de serviços básicos e de políticas públicas que notadamente atingem a maior parte da população rural no Brasil, prejudicam mais fortemente as mulheres, pois a esse conjunto de vulnerabilidades sociais somam-se as desigualdades específicas de gênero que se constituem enquanto fatores de vulnerabilidade não apenas em relação ao desenvolvimento social e econômico dessas mulheres, mas, sobretudo, em relação à saúde (Heredia \& Citrão, 2006). Devemos levar em consideração que as mulheres que se encontram em situação de pobreza ou extrema pobreza, em geral, estão mais expostas a condições de vida adversas, muitas vezes vivendo em contextos de violência e precariedade infraestrutural que representam agravos à saúde global dos indivíduos. Por tal razão, Zanello e Silva (2012) marcam a necessidade de questionar se tais diagnósticos apontam para um quadro médico ou se o que se está produzindo não seria um processo de medicalização da pobreza e das mazelas sociais.

Acreditamos, portanto, que o uso da categoria gênero explicita a assimetria existente nos mecanismos de construção social da realidade e a maneira como se estabelecem relações entre homens e mulheres no interior da sociedade como um vetor que permeia a produção das subjetividades e, consequentemente, as interpretações sobre o adoecimento psíquico. Dessa forma, reafirmamos a importância de conhecer e entender os contextos que produzem processos de saúde/doença, questionando as concepções reducionistas e biologizantes acerca da saúde mental e reforçando o diálogo entre o campo dos estudos de gênero e saúde de forma a elaborar intervenções e política públicas que deem conta das demandas da população e de processos de transformação da realidade dessas mulheres.

Por fim, ressaltamos que ao adotarmos uma perspectiva de multideterminação da saúde (social, ambiental, econômica, cultural e política) pretendemos ampliar, em estudos futuros, as relações para além do questionário sócio-demográfico -ambiental, introduzindo instrumentos mais direcionados, a exemplo da avaliação do Índice de Pobreza Multidimensional, Escala de Apoio Social e Escala de Bem-estar Pessoal (Cummins, Eckersley, Pallant, Van Vugt, \& Misajon, 2003) buscando estabelecer relações mais consistentes entre esses fatores.

\section{Referências}

Álvaro, J. L., Torregrosa, J. R., \& Luque, A. G. (1992). Estructura social y salud mental. In J. L. Álvaro, A. G. Luque, \& J. L. A. Estramiana (Orgs.), Influencias sociales y psicológicas en la salud mental (pp. 9-30). Madrid: Siglo Veintiuno Editores. 
Alves, P. C. B., \& Rabelo, M. C. M. (1999). Significação e metáforas na experiência da enfermidade. In M. C. M. Rabelo, P. C. B. Alves, \& I. M. A. Souza (Orgs.), Experiência da doença e narrativa (pp. 171-186). Rio de Janeiro: Editora Fiocruz.

Araújo, T. M., Pinho, P. S., \& Almeida, M. M. G. (2005). Prevalência de transtornos mentais comuns em mulheres e sua relação com as características sociodemográficas e o trabalho doméstico. Revista Brasileira de Saúde Materno Infantil, 5(3), 337-348. doi: 10.1590/S151938292005000300010

Aucélio, P. Q., Godoi, A., \& Morais, M. (Coord.) (2001). Saúde dos trabalhadores rurais de assentamentos e acampamentos de reforma agrária. Brasília: UNB.

Bandeira, M., Freitas, L. C., \& Carvalho Filho, J. (2007). Avaliação da ocorrência de transtornos mentais comuns em usuários do Programa de Saúde da Família. Jornal Brasileiro de Psiquiatria, 56(1), 41- 47. doi: 10.1590/S004720852007000100010

Bardin, L. (1977). Análise de conteúdo. Lisboa: Edições 70

Bergamasco, S. M. P., \& Norder, L. A. C. (1996). O que são assentamentos rurais. São Paulo: Ed. Brasiliense.

Butto, A. (2011). Políticas para as mulheres rurais: Autonomia e cidadania. In A. Butto \& I. Dantas (Orgs.), Autonomia e cidadania: Políticas de organização produtiva para as mulheres no meio rural (pp.11-35). Brasília: Ministério do Desenvolvimento Agrário.

Campos, C. S. S. (2011). A face feminina da pobreza em meio à riqueza do agronegócio. Buenos Aires: Clacso/Outras Expressões.

Carneiro, F. F., Tambellini, A. T., Silva, J. A., Haddad, J. P. A., Búrigo, A. C., Sá, W. R., ... Bertolini, V. A. (2008). Saúde de famílias do Movimento dos Trabalhadores Sem Terra e de bóias-frias, Brasil, 2005. Revista de Saúde Pública, 42(4), 757-763. doi: 10.1590/S0034-89102008005000037

Confederação Nacional dos Trabalhadores na Agricultura (2008). Combate à violência contra as mulheres trabalhadoras rurais. Brasília: Comissão Nacional de Mulheres Trabalhadoras Rurais.

Cordeiro, R. (2007). Gênero em contextos rurais: A liberdade de ir e vir e o controle da sexualidade das mulheres no Sertão de Pernambuco. In A. M. Jacó-Vilela \& L. Sato (Orgs.), Diálogos em Psicologia Social (pp. 131-139). Porto Alegre: Editora Evangraf Ltda.

Costa, A. G., \& Ludermir, A. B. (2005). Transtornos mentais comuns e apoio social: Estudo em comunidade rural da Zona da Mata de Pernambuco, Brasil. Cadernos de Saúde Pública, 21(1), 73-79. doi: 10.1590/S0102311X2005000100009

Coutinho, M. P. L., Rodrigues, I. F., \& Ramos, N. (2012). Transtornos mentais comuns no contexto migratório internacional. Psico, 43(3), 400-407. Recuperado de http://revistaseletronicas.pucrs.br/revistapsico/ojs/ index.php/revistapsico/article/view/10512/8241

Cummins, R. A., Eckersley, R., Pallant, J., Van Vugt, J., \& Misajon, R. (2003). Developing a national index of subjective wellbeing: The Australian Unity Wellbeing Index. Social Indicators Research, 64(2), 159-190. doi: 10.1023/A:1024704320683

Dejours, C. (1992). A loucura do trabalho: Estudo de psicopatologia do trabalho. São Paulo: Cortez.

Delgado, G. C. (2001). Expansão e modernização do setor agropecuário nos pós- guerra: Um estudo da reflexão agrária. Estudos Avançados (15)43, 157-172.

Duarte, L. F. D. (1986). Da vida nervosa nas classes trabalhadoras urbanas. Rio de Janeiro: Zahar.

Duarte, L. F. D. (1994). A outra saúde - mental, psicossocial, físico-moral? In P C. Alves \& M. C. S. Minayo (Orgs.), Saúde e doença: Um olhar antropológico (pp.83-90). Rio de Janeiro: Editora Fiocruz.

Duarte, L. F. D. (2003). Indivíduo e pessoa na experiência da saúde e da doença. Ciência \& Saúde Coletiva, 8(1), 173-183. doi: 10.1590/S141381232003000100013

Faria, N. M. X., Facchini, L. A., Fassa, A. G., \& Tomasi, E. (2000). Processo de produção rural e saúde na Serra Gaúcha: Um estudo descritivo. Cadernos de Saúde Pública, 16(1), 115-128. doi: 10.1590/S0102-311X2000000100012
Fontoura Junior, E. E., Souza, K. R., Renovato, R. D., \& Sales, C. M. (2012) A relação de saúde e trabalho em um assentamento do MST na região de Fronteira Brasil - Paraguai. Trabalho, Educação e. Saúde, 9(3), 379-397. doi: 10.1590/S1981-77462011000300003

Golberg, D., \& Huxley, P. (1992). Common mental disorders: A bio-social model. Londres; Nova Iorque: Tavistock; Routledge.

Heredia, B. M. A., \& Citrão, R. P. (2006). Gênero e acesso a políticas públicas no meio rural brasileiro. In L. L. Barsted, J. Pitanguy, \& M. Dayse (Orgs.) O progresso das mulheres no Brasil (pp. 102-131). São Paulo: Fundo de Desenvolvimento das Nações Unidas para a Mulher

Iacoponi, E., \& Mari, J.J. (1988). Reliability and factor structure of the Portuguese version of self-reporting questionnaire. International Journal of Social Psychiatry, 1(3), 213-222. doi: 10.1177/002076408903500301

Instituto Brasileiro de Geografia e Estatística (2010). Reforma agrária: Pesquisa sobre a qualidade de vida, produção e renda dos assentamentos da reforma agrária. Recuperado de http://www.pqra.incra.gov.br.

Instituto Brasileiro de Geografia e Estatística (2011). Pesquisa nacional por amostra de domicílios. Recuperado de http://www.sidra.ibge.gov.br.

Instituto Brasileiro de Geografia e Estatística (2013). Levantamento sistemático da produção agrícola do ano de 2012. Recuperado de www.ibge.gov.br/ home/estatistica/indicadores/agropecuaria/lspa/lspa_201202.pdf.

Instituto Nacional de Colonização e Reforma Agrária (2012). Projetos de reforma agrária conforme fases de implementação. Recuperado de http:// www.incra.gov.br/index.php/reforma-agraria-2/questao-agraria/ numeros-da-reforma-agraria/file/31-relacao-de-projetos-de-reformaagraria.

Ludermir, A. B. (2008). Desigualdades de classe e gênero e saúde mental nas cidades. Physis: Revista de Saúde Coletiva, 18(3), 451-467. doi: 10.1590/ S0103-73312008000300005

Ludermir, A. B., \& Melo Filho, D.A. (2002). Condições de vida e estrutura ocupacional associadas a transtornos mentais comuns. Revista de Saúde Pública, 36(2), 213-219. doi: 10.1590/S0034-89102002000200014

Maciel, R. H. M., Rigotto, R. M., \& Alves, P. A. (2011). Como está a saúde desses trabalhadores? In R. Rigotto (Org.), Agrotóxicos, trabalho e saúde: Vulnerabilidade e resistência no contexto da modernização agrícola no baixo Jaguaribe/CE (pp. 391-413). Fortaleza: Universidade Federal do Ceará/ Expressão Popular

Maragno, T. M., Goldbaum, M., Giani, R. J., Novaes, H. M. D., \& Cesar, C. L. G. (2006). Prevalência de transtornos mentais comuns em populações atendidas pelo programa saúde da família (QUALIS) no município de São Paulo, Brasil. Cadernos de Saúde Pública, 22(8), 1639-1648. doi: 10.1590/ S0102-311X2006000800012

Mari, J. J., \& Williams, P. (1986). A validity study of a psychiatric screening questionnaire (SRQ-20) in primary care in the city of São Paulo. Brazilian Journal of Psychiatry. 148, (23-26. doi: 10.1192/bjp.148.1.23

Melo, H. P., \& Di Sabbato, A. (2009). Gênero e trabalho rural. In A. Butto (Org.) Estatísticas rurais e a economia feminista: Um olhar sobre o trabalho das mulheres (pp. 31-117). Brasília: Ministério do Desenvolvimento Agrário.

Melo, H. P., Cappelin, P., \& Castro, E. G. (2008). Agricultura familiar nos assentamentos rurais: Nas relações entre as mulheres e os homens - o caso do Pontal do Paranapanema. In A. Lopes \& A. Butto (Orgs.), Mulheres na reforma agrária: A experiência recente no Brasil (pp.81-151). Brasília: Ministério do Desenvolvimento Agrário.

Ministério da Saúde (2005). Plano nacional de saúde: Um pacto pela saúde no Brasil. Brasília: Ministério da Saúde. Recuperado de http://dtr2001.saude. gov.br/editora/produtos/livros/pdf/05_0306_M.pdf.

Ministério do Desenvolvimento Agrário (2011). Estatísticas do meio rural 2010 2011. São Paulo: DIEESE;NEAD;MDA

Neves M. Y. R., \& Silva, E. S. (2006). A dor e a delícia de ser (estar) professora: Trabalho docente e saúde mental. Estudos e Pesquisas em Psicologia, 6(1) 63-75. Recuperado de http://pepsic.bvsalud.org/scielo.php?script=sci arttext\&pid=S1808-42812006000100006\&lng=pt\&tlng=pt.

Oliveira-Couto, V. (2007). Vida de mulher: Gênero, pobreza, saúde mental e resiliência (Dissertação de Mestrado). Universidade 
de Brasília, Brasília. Recuperado de http://repositorio.unb.br/ bitstream/10482/2862/1/22007_VeruscaCoutodeOliveira.pdf.

Pinheiro, T. M., Silva, J. M., Carneiro, F., Faria, H., \& Silva, E. (2009). Saúde no campo. In A. Miranda (Coord.), Cadernos de textos da $1^{a}$ Conferência Nacional de Saúde Ambiental (pp. 25-29). Brasília: Associação Brasileira de Saúde Coletiva.

Ribeiro, W. S., Andreoli, S. B., Ferri, C. P., Prince, M., \& Mari, J. J. (2009). Exposição à violência e problemas de saúde mental em países em desenvolvimento: Uma revisão da literatura. Revista Brasileira de Psiquiatria, 31(Suppl. 2), S49-S57. Recuperado de http://www.scielo.br/ scielo.php?script=sci_arttext\&pid=S1516-44462009000600003\&lng=en \&tlng=pt. 10.1590/S1516-44462009000600003.

Santos, A. M. C. C. (2009). Articular saúde mental e relações de gênero: Dar voz aos sujeitos silenciados. Ciência \& Saúde Coletiva, 14(4), 1177-1182. doi: $10.1590 /$ S1413-81232009000400023

Secretaria de Políticas para as Mulheres (2004). Plano nacional de políticas para mulheres. Brasília: SPM. Recuperado de http://bvsms.saude.gov.br/bvs/ publicacoes/pnpm_compacta.pdf

Silva, C. (2011). Pensar o futuro, bem viver o presente. Cadernos de Crítica Feminista, 5(4), 100-111.

Silva, D. F., \& Santana, P. R. (2012). Transtornos mentais e pobreza no Brasil: Uma revisão sistemática. Tempus - Actas de Saúde Coletiva, 6(4), 175 185. Recuperado de http://www.tempusactas.unb.br/index.php/tempus/ article/view/1214/1099

World Health Organization (2000). Women and mental health. Recuperado de www.who.int/mediacentre/factsheets/fs248/en.

World Health Organization (2002). Gender and mental health. Recuperado de www.who.int/gender.

Zanello, V., \& Silva, R. M. C. (2012). Saúde mental, gênero e violência estrutural. Revista Bioética, 20(2), 267-279. Recuperado de http://revistabioetica. cfm.org.br/index.php/revista_bioetica/article/view/745

Notas

1. Programa do governo federal de transferência de renda com condicionalidades, que compreende atualmente a transferência de benefícios monetários, entre $R \$ 32,00$ e $R \$ 306,00$, para famílias que tenham renda mensal per capita de até $\mathrm{R} \$$ 140,00 , sendo estruturado em três eixos principais: transferência de renda, condicionalidades e programas complementares.

2. O conceito de "feminização da pobreza" procura explicitar a grande presença de mulheres entre os pobres, seu aumento progressivo e os condicionantes dessa realidade.

3. Os nomes de nossas interlocutoras foram modificados para que suas identidades fossem preservadas.

4. Técnica agrícola de cultivo em territórios com baixos índices de chuva e sem irrigação.

5. As famílias devem assumir e cumprir condicionalidades para receber o benefício, como manter as crianças e adolescentes matriculados na escola com frequência mínima de $85 \%$; acompanhamento do cartão de vacinação e o crescimento e desenvolvimento das crianças; acompanhamento da saúde das mulheres se gestantes ou lactantes com realização de exame pré-natal; entre outros.

6. Lei número $11.340 / 2006$ que aumentou o rigor das punições das agressões contra as mulheres ocorridas no âmbito doméstico ou familiar e criou mecanismos de prevenção das situações de violência, ampliando a rede assistencial. 
Maria da Graça Silveira Gomes da Costa, Mestrado em Psicologia pela Universidade Federal do Rio Grande do Norte (UFRN), é Professora do curso de Psicologia da Universidade Potiguar (UnP). Endereço para correspondência: Rua da Campina, 140, Apto. B-1307, Ponta Negra, Natal - RN. Cep: 59090-480. Telefone: (84) 9683-1890. E-mail: mariaggomes@gmail.com

Magda Diniz Bezerra Dimenstein, Doutora em Ciências da Saúde pelo Instituto de Psiquiatria da Uinversidade Federal do Rio de Janeiro (UFRJ), Pós-Doutora em Saúde Mental pela Universidad Alcalá de Henares/ES, é Professora Titular do Departamento de Psicologia da Universidade Federal do Rio Grande do Norte (UFRN). E-mail: magda@ufrnet.br

Jáder Ferreira Leite, Doutor em Psicologia Social pela Universidade Federal do Rio Grande do Norte (UFRN), é Professor Adjunto III do Departamento de Psicologia da Universidade Federal do Rio Grande do Norte (UFRN). E-mail: jaderfleite@gmail.com 